\title{
Under- and overreporting of energy in a group of candidates for CABG surgery and its association with some anthropometric and sociodemographic factors, Tehran, Iran
}

\author{
Bahareh Amirkalali' \\ Mehdi Najafi \\ Asal Ataie-Jafari' \\ Saeed Hosseinil \\ Ramin Heshmat' \\ 'Nutrition Department, The \\ Endocrinology and Metabolism \\ Research Centre (EMRC) of Tehran \\ University of Medical Sciences \\ (TUMS), Tehran, Iran; ${ }^{2}$ Tehran Heart \\ Center, Tehran, Iran
}

\begin{abstract}
Introduction: Numerous studies have documented a high prevalence of misreporting energy intakes. This paper examines the prevalence of under- and overreporting of energy intake in a group of candidates for coronary artery bypass graft (CABG) surgery and its association with body mass index (BMI) and some sociodemographic factors.

Subjects and methods: Dietary assessment (using a food frequency questionnaire) and demographic evaluation of 449 CABG surgery candidates was performed. Weight and height was also measured. McCrory equation was used to identify inaccurate records of energy intake. With this equation, reporting energy intake less than $78 \%$ and more than $122 \%$ of predicted energy expenditure was considered as under- and overreporting, respectively.

Results: Less than half of the participants reported energy intakes within the plausible limits. There were more overreporters than underreporters in this sample. The only significant association between misreporting and related factors was seen in BMI groups. As BMI increased, the number of underreporters increased significantly. Expressed as a percentage of total energy, mean carbohydrate intake was significantly lower and mean fat and protein intake was significantly higher in underreporters compared to overreporters.
\end{abstract}

Conclusion: The high prevalence of misreporting suggests more research to examine the characteristics of misreporters. Calibrating data with these characteristics can help to improve intake estimates.

Keywords: underreporting, overreporting, energy intake, CABG candidates

\section{Introduction}

Numerous studies in industrialized countries have documented a high prevalence of underreporting energy intakes from 24-hour recalls, food records, and food-frequency questionnaires (FFQs) (Heitmann and Lissner 1995; Hirvonen et al 1997; Lafay et al 1997; Goris et al 2000; Krebs-Smith et al 2000). Many of these studies have shown that underreporting is not random, but is related to characteristics such as obesity, smoking, dieting, and psychological factors (Hebert et al 1995; Voss et al 1997; Braam et al 1998; Johansson et al 1998, 2001).

Most of these studies have been performed on a healthy population (Heitmann and Lissner 1995; Hebert et al 1995; Hirvonen et al 1997; Lafay et al 1997; Voss et al 1997; Braam et al 1998; Johansson et al 1998, 2001; Goris et al 2000; Krebs-Smith et al 2000), but it is clear that accurate evaluation of dietary intake is very important in some diseases such as cardiovascular problems where lifestyle, especially diet, has a great effect on their procedure. Therefore, coronary artery bypass graft (CABG) candidates were the study population. 
The doubly labeled water technique, which measures the total energy expenditure of subjects in free-living situations (Schoeller 1999, 2002) can be used to validate reported energy intakes but because of its high cost, it can not be used in all occasions. As an alternative approach to detect misreporting of energy intake, Goldberg and colleagues (1991) introduced the ratio of reported energy intake to basal metabolic rate (rEI/BMR). This method assesses the validity of $r E I$ by comparing total energy expenditure (TEE) with rEI when both are expressed as a multiple of basal metabolic rate (BMR). The use of Goldberg cut-off for doing so has marked limitations. Most notably, in order to use the Goldberg cut-off, it is necessary to make an assumption of a certain physical activity level (PAL) for each individual. However, the error in assigning PAL is one source of variability that is not accounted for by Goldberg and colleagues (1991) or Black (2000) in their analyses. The second limitation of the Goldberg cut-off is that although both underreporting and overreporting can occur to varying degrees, it only identifies extremely inaccurate reporting (ie, $2 \mathrm{SD}$ for the agreement between $\mathrm{rEI} / \mathrm{BMR}$ and PAL). This may be one reason why some investigators have used the percentage difference between rEI and either measured or predicted TEE to identify inaccurate reports and determine the degree of misreporting in individuals. However, this method is technically incorrect when applied to individual reports because it does not take into account any errors in the methods used to quantify TEE and rEI. So we used an alternative approach for identifying inaccurate records of dietary energy intake created by McCrory and colleagues (2002), in part based on the reasoning outlined by Goldberg and colleagues (1991) and more recently by Black (2000). While this method uses the percentage difference between total energy expenditure predicted from published equations (pTEE) and rEI, it also takes into account the within-subject errors in these parameters. Since TEE is predicted from Vinken equation (Vinken et al 1999), use of this method should theoretically eliminate the potential error of assigning inaccurate PALs with only limited information on the activity of individuals under study. Furthermore, since pTEE is based on the simple parameters of age, weight, height, and sex, it can be used when there is little or no information available to help investigators assign an appropriate PAL.

The aim of this study was to evaluate the prevalence of under- and overreporting of energy intake in a group of candidates for $\mathrm{CABG}$ surgery and its association with body mass index (BMI) and some sociodemographic factors.

\section{Subjects and methods Subjects}

The study was carried-out between March-July 2006. Subjects in this study were patients being admitted to the cardiothoracic ward for CABG surgery at Tehran Heart Center. The final analytic sample in this study consisted of 449 patients (328 men and 121 women) aged 35-80. Informed consent was obtained from each participating subject. The study was approved by Tehran Heart Center, Tehran University of Medical Sciences.

\section{Anthropometric measures}

Anthropometric measurement was performed by a trained dietician for each patient. Weight was measured without shoes and with light clothing using digital scales and recorded to the nearest $100 \mathrm{~g}$. Height was measured to the nearest $0.5 \mathrm{~cm}$ by using a tape measure while the subjects were standing, not wearing shoes and had the shoulders in a normal position. BMI was calculated as weight (in $\mathrm{kg}$ ) divided by height $\left(\right.$ in $^{2}$ ) and it was used to classify subjects as normal $\left(<18.5-24.9 \mathrm{~kg} / \mathrm{m}^{2}\right)$, overweight (25-29.9) and obese ( $\geq 30)$.

\section{Sociodemographic and dietary assessment}

A FFQ to assess the habitual dietary patterns of patients and a demographic questionnaire were administered by a trained dietitian to each patient. The semiquantitative FFQ was a version of a 168-item questionnaire and it was previously validated on a sample of healthy population and revealed good correlations between dietary intakes assessed by a similar FFQ and those from multiple days of 24-h dietary recalls (Esmaillzadeh et al 2005). It consisted of standard serving sizes commonly consumed by Iranians. Participants were asked to report how often they consumed each of the food items listed in the questionnaire as the number of times per day, per week, per month, or per year during the previous year.

Analysis of consumed foods was carried out by Nutritionist III software modified for Iranian foods composition (percentage of total energy intake from carbohydrate, protein, and fat) was examined to assess which part was misreported in under- and overreporters.

\section{Characterizing under- and overreporters}

The Vinken equation (Vinken et al 1999) used for predicting TEE is as follows:

$$
\begin{aligned}
& \text { pTEE }=7.377-0.073 \times \text { age } 0.0806 \times \text { weight }+0.0135 \\
& \times \text { height }-1.363 \times \operatorname{sex}
\end{aligned}
$$


Where age is in years, weight is in $\mathrm{kg}$, height is standing height in $\mathrm{cm}$, and sex is 0 for men and 1 for women.

McCory equation was used to calculate cut-off points for detecting under- and overreporters (McCrory et al 2002).

$$
\begin{aligned}
\pm 1 \mathrm{SD} & =\sqrt{\left.C V^{2}{ }_{w E I} / d\right)+C V^{2}{ }_{w T E E}} \\
& =\sqrt{\left(C V^{2}{ }_{w E I} / d\right)+C V^{2}{ }_{w P T E E}+C V^{2}{ }_{t m T E E}}
\end{aligned}
$$

Values of $8.2 \%$ for CVtmTEE (within subject coefficient of variation in measured total energy expenditure), which includes the technical error of measuring TEE by the doubly labeled water method as well as biological variation (Black 2000; McCrory et al 2002), 13.9\% for CVwpTEE (within-subject coefficient of variation in predicted total energy expenditure), $44 \%$ for CVwEI (within-subject coefficient of variation in energy intake), and 1 for $d$ (the number of days of energy intake measurement) were used in this equation for this study.

Using the above formula, the $\pm 1 \mathrm{SD}$ for the agreement between $\mathrm{rEI}$ and pTEE is $\pm 22 \%$. Reporting energy intake less than $78 \%$ and more than $122 \%$ of predicted energy expenditure was considered as underreporting and overreporting, respectively. Characteristics associated with misreporting such as age, BMI, sex, education, and smoking were then identified (Lafay et al 1997; Braam et al 1998; Johansson et al 2001).

\section{Data analysis}

Patients were categorized into four age groups (30-49, $50-59, \geq 60)$, three BMI groups $(<18.5-24.9,25-29.9, \geq 30)$ and three education levels (primary education defined as primary school or less; secondary education characterized as secondary school level; and high education defined as university/college levels or equivalents). Subjects were classified as nonsmokers (if they had never smoked cigarettes), and current smokers (if they were currently smoking one or more cigarettes per day on a regular daily basis). Pearson correlation test, student t-test and oneway analysis of variance for continuous variables and chi-square test for categorical variables were used to determine whether associations were significant $(\mathrm{P}<0.05)$. Analysis was conducted using SPSS version 11.5 (SPSS Inc., Chicago, IL, USA).

\section{Results}

Most of the patients were male (73\%), 50 year or older $(84.6 \%)$, over weight or obese $(71 \%)$, non-smoker $(65 \%)$ and with primary education (54\%). Mean reported energy intake was significantly higher than mean predicted energy expenditure $(p<0.01)$. Less than half of the participants
(48\%) reported energy intakes within the limits defined as plausible. There were more overreporters than underreporters in this sample (29\% vs $23 \%$ ). Compared to males, females were significantly likely to be more overweight or obese, older, and nonsmoker (Table1).

Women were equally under- and overreporters (28\%) but men were more overreporters (29\% vs 21\%) (Table 2).

The only significant association between misreporting and related factors was seen in BMI groups. Overweight and obese subjects were more prevalent in underreporters than plausible and overreporters $(81.7 \%$ vs $68.4 \%$ and $65.4 \%$, respectively, $\mathrm{p}<0.01)$. As BMI increased, the number of underreporters also increased significantly. Both chi-square trend and one-way ANOVA tests showed the same result (Table 2). Pearson correlation test showed a significant negative association only between BMI and percentage of reported energy intake from predicted energy expenditure $(\mathrm{r}=-0.15$, $\mathrm{p}=0.001)$. The result was the same when men and women were analyzed separately (not shown).

Mean carbohydrate intake expressed as a percentage of total energy was significantly lower and mean fat and protein intake expressed as a percentage of total energy was significantly higher in underreporters compared with overreporters (Table 3). Pearson correlation also showed that as percentage of reported energy intake from predicted energy expenditure increased proportion of carbohydrate intake (expressed as a percentage of total energy intake) increased $(\mathrm{r}=0.2, \mathrm{p}<0.001)$ and proportion of fat and protein intake (expressed as a percentage of total energy intake) decreased $(\mathrm{r}=-0.148, \mathrm{p}<0.01 ; \mathrm{r}=-0.268, \mathrm{p}<0.001)$.

\section{Discussion}

Exact evaluation of dietary intake is very important especially in cardiovascular patients. As all the other studies in this field worked on healthy people, we decided to choose CABG candidates as our study population. Other studies had used Goldberg cut-offs or percentage difference of rEI and mTEE to detect misreporters of energy intake but because of several limitations in using these methods (mentioned in the introduction) we used McCrory equation instead. As far as we know no study has used this equation to be exactly comparable with our research.

Both under- and overreporting of energy intakes were highly prevalent in this study. Underreporting (28\% of women, $21 \%$ of men) was similar to levels reported in numerous studies in industrialized countries using FFQ data, in which prevalence generally ranged from $21 \%$ to $45 \%$ (Johansson et al 1998; Samaras et al 1999; Mennen et al 2000; Horner et al 2002; Mirmiran et al 1382). Overreporting 
Table I Characteristics of the subjects $(N=449)$ Values are expressed as mean \pm standard deviation, unless specified otherwise

\begin{tabular}{|c|c|c|c|c|}
\hline Variables N (\%) & & All 449 & Female I 2 I (26.9) & Male $328(73.1)$ \\
\hline \multirow[t]{4}{*}{ Age (years) } & & $58.9 \pm 9$ & $59.5 \pm 7.5$ & $58.7 \pm 9.5$ \\
\hline & $30-49$ & $69(15.4)$ & $10(8.3)$ & $59(18)$ \\
\hline & $50-59$ & $164(36.5)$ & $50(4 I .3)$ & II 4 (34.8) \\
\hline & $\geq 60$ & $216(48.1)$ & $61(50.4)$ & $155(47.3)$ \\
\hline Body weight (kg) & & $74 \pm 11.07$ & $69.9 \pm 10.8$ & $75.5 \pm 10.7$ \\
\hline \multirow[t]{4}{*}{ Body mass index $\left(\mathrm{kg} / \mathrm{m}^{2}\right)$} & & $27.4 \pm 4$ & $29.5 \pm 4.6$ & $26.6 \pm 3.4$ \\
\hline & $<18.5-24.9$ & $132(29.4)$ & $23(19)$ & $109(33.2)$ \\
\hline & $25-29.9$ & $198(44.1)$ & $42(34.7)$ & $156(47.6)$ \\
\hline & $\geq 30$ & $119(26.5)$ & $56(46.3)$ & $63(19.2)$ \\
\hline Reported energy intake (kcal) & & $282 I \pm 1250$ & $2327 \pm 887$ & $3004 \pm 1315$ \\
\hline $\begin{array}{l}\text { Predicted energy } \\
\text { requirement (kcal) }\end{array}$ & & $2604 \pm 362$ & $2242 \pm 275$ & $2737 \pm 293$ \\
\hline \multirow{4}{*}{$\begin{array}{l}\text { \% Reported from predicted } \\
\text { energy intake }\end{array}$} & & $108.8 \pm 45$ & $104.4 \pm 38$ & $110.4 \pm 47.8$ \\
\hline & Underreporters & $104(23.1)$ & $34(28.1)$ & $70(21.3)$ \\
\hline & Plausible reporters & $215(47.9)$ & $53(43.8)$ & $162(49.4)$ \\
\hline & Overreporters & $130(29)$ & $34(28.1)$ & $96(29.3)$ \\
\hline \multirow[t]{2}{*}{ Smoker } & Yes & $156(34.7)$ & I I 8 (97.5) & $175(53.4)$ \\
\hline & No & $293(65.3)$ & $3(2.5)$ & $153(46.6)$ \\
\hline \multirow[t]{3}{*}{ Education } & Primary education & $243(54.1)$ & $69(57)$ & $174(53)$ \\
\hline & Secondary education & $138(30.7)$ & $34(28.1)$ & $104(31.7)$ \\
\hline & High education & $68(15.1)$ & I8 (I4.9) & $50(15.3)$ \\
\hline
\end{tabular}

( $29 \%$ of men, $28 \%$ of women) was substantially higher than previous studies that reported such data, where levels were 5\%-7\% (Johansson et al 1998; Mirmiran et al 1382).

In this study, as BMI increased, the number of underreporters increased. The strong relationship between obesity and underreporting is consistent with other studies in both industrialized (Lissner et al 2000) and developing countries (Harrison et al 2000; Winkvist et al 2002; Mirmiran et al 1382). None the less, underreporting appears to have increased over time in developed countries (Hirvonen et al

Table 2 Association between sociodemographic characteristics and misreporting of energy intake

\begin{tabular}{|c|c|c|c|c|c|}
\hline & & $\begin{array}{l}\% \text { rEI from pEI } \\
\text { Mean } \pm \text { SD }\end{array}$ & $\begin{array}{l}\text { Underreporters } \\
\text { (\%) }\end{array}$ & $\begin{array}{l}\text { Plausible reporters } \\
\text { (\%) }\end{array}$ & $\begin{array}{l}\text { Overreporters } \\
\text { (\%) }\end{array}$ \\
\hline \multirow[t]{3}{*}{ Age } & $30-49$ & $111.9 \pm 56.3$ & 24.6 & 44.9 & 30.4 \\
\hline & $50-59$ & $104.5 \pm 40.5$ & 29.9 & 44.5 & 25.6 \\
\hline & $\geq 60$ & $\mathrm{III} \pm 45 . \mathrm{I}$ & 17.6 & 51.4 & 31 \\
\hline \multirow[t]{3}{*}{ BMI } & $<18.5-24.9$ & $116.1 \pm 49^{b}$ & $14.4^{\mathrm{a}}$ & 51.5 & 34.1 \\
\hline & $25-29.9$ & $108.2 \pm 44.5$ & 22.2 & 52.5 & 25.3 \\
\hline & $\geq 30$ & $101.6 \pm 41.7$ & 34.5 & 36.1 & 29.4 \\
\hline \multirow[t]{2}{*}{ Sex } & Male & $110.4 \pm 47.8$ & 21.3 & 49.4 & 29.3 \\
\hline & Female & $104.4 \pm 38.2$ & 28.1 & 43.8 & 28.1 \\
\hline \multirow[t]{2}{*}{ Smoker } & Yes & $112.4 \pm 48.8$ & 18.6 & 53.2 & 28.2 \\
\hline & No & $106.8 \pm 43.5$ & 25.6 & 45.1 & 29.4 \\
\hline \multirow[t]{3}{*}{ Education } & Primary education & $107.1 \pm 47.9$ & 25.9 & 48.1 & 25.9 \\
\hline & Secondary education & $112.1 \pm 43.7$ & 21 & 44.9 & 34.1 \\
\hline & High education & $108 \pm 39.4$ & 17.6 & 52.9 & 29.4 \\
\hline
\end{tabular}

Abbreviations: BMI, body mass index; rEl, reported energy intake; $\mathrm{pEl}$, predicted energy intake; SD, standard deviation.

Notes: ${ }^{a}$ Statistically significant differences across BMI groups in underreporters; 'Statistically significant different from the group with BMI $\geq 30$. 
Table 3 Association between food composition (percentage of macronutrients from energy intake) and misreporting of energy intake

\begin{tabular}{llll}
\hline & Underreporters $($ mean \pm SD) & Plausible reporters (mean \pm SD) & Overreporters $($ mean \pm SD) \\
\hline Carbohydrate & $58.49 \pm 7.25$ & $60.31 \pm 6.71$ & $62.54 \pm 8.32^{\mathrm{a}}$ \\
Protein & $16.11 \pm 2.66^{\mathrm{b}}$ & $14.89 \pm 2.30$ & $13.83 \pm 2.7^{\mathrm{a}}$ \\
Fat & $27.95 \pm 6.20^{\mathrm{c}}$ & $27.29 \pm 6.16$ & $25.78 \pm 8.39$ \\
\hline
\end{tabular}

Notes: ${ }^{\mathrm{a}} \mathrm{p}<0.001, \mathrm{p}<0.05$ versus plausible and underreporters; ${ }^{\mathrm{b}} \mathrm{p}<0.001, \mathrm{p}<0.001$ versus plausible and overreporters; ${ }^{\mathrm{c}} \mathrm{p}=0.05$ versus overreporters.

1997; Heitmann et al 2000) while obesity levels, as well as the dissemination of dietary messages related to obesity, have been increasing. However, it is not clear why some obese individuals underreport, while others do not. In this sample one third of obese and overweight women and one forth of all obese and overweight men were underreporters. On the other hand as we can see a substantial proportion of normal weight men (14.7\%) and women (13\%) were underreporters. So other characteristics than obesity may induce underreporting. Besides obesity, however, less is known about other characteristics of underreporters. In this study, underreporting was not significantly associated with older age, education level, smoking, and sex.

While associations with BMI have been fairly consistent (Harrison et al 2000; Lissner et al 2000; Winkvist et al 2002; Mirmiran et al 1382), other characteristics may vary across populations. For example, significant positive associations with college education were reported in some (Johansson et al 1998) but not all (Heitmann 1993) studies. Several studies reported positive associations with smoking (Johansson et al 1998); however, negative or no associations have also been reported (Heitmann 1993; Pryer et al 1997). Using different methods to evaluate dietary intake ( $24 \mathrm{~h}$ food recall. 3 day food records, FFQ, etc), their degree of validity and reliability and different cut-off points for diagnosing under- and overreporters can partly explain the different results found in these studies.

In this study we examined whether low-energy reporters underreported all macronutrients equally or reported some lower than others. Energy from carbohydrate was significantly lower, whereas those from fat and protein were significantly higher, in underreporters (Table 3 ) but according to the review by Livingstone and Black (2003), energy from fat tends to be reported significantly lower in low-energy reporters. This controversy may be the result of high fat content of protein foods which was consumed more by underreporters.

\section{Conclusion}

The high prevalence of both under- and overreporting suggests the need to explore alternative techniques for collecting dietary data. More research is also needed to examine the characteristics of under- and overreporters. Calibrating data, with incorporating characteristics of misreports can help to improve intake estimates.

Our study found a significant correlation between BMI and misreporting energy intake so BMI should be taken into consideration while analyzing dietary data. However, the participants in this study were cardiovascular patients. Further studies are needed to examine whether the correlations observed in the present study are commonly observed in other groups as well.

\section{Acknowledgment}

This research was supported by Tehran Heart Center, and The Endocrinology and Metabolism Research Centre (EMRC) of Tehran University of Medical Sciences. The authors report no conflicts of interest in this work.

\section{References}

Black AE. 2000. Critical evaluation of energy intake using the Goldberg cut-off for energy intake: basal metabolic rate. A practical guide to its calculation, use and limitations. Int J Obes Relat Metab Disord, 24:1119-30.

Braam LA, Ocke MC, Bueno-de-Mesquita HB, et al. 1998. Determinants of obesity-related underreporting of energy intake. Am J Epidemiol, 147:1081-6.

Esmaillzadeh A, Mirmiran P, Azizi F. 2005. Whole-grain intake and the prevalence of hypertriglyceridemic waist phenotype in Tehranian adults. Am J Clin Nutr, 81:55-63.

Goldberg GR, Black AE, Jebb SA, et al. 1991. Critical evaluation of energy intake data using fundamental principles of energy physiology. 1. Derivation of cut-off values to identify under-recording. Eur J Clin Nutr, 45:569-81.

Goris AH, Westerterp-Plantenga MS, Westerterp KR. 2000. Under eating and under recording of habitual food intake in obese men: selective underreporting of fat intake. Am J Clin Nutr, 71:130-4.

Harrison GG, Galal OM, Ibrahim N, et al. 2000. Underreporting of food intake by dietary recall is not universal: a comparison of data from Egyptian and American women. J Nutr, 130:2049-54.

Hebert JR, Clemow L, Pbert L, et al. 1995. Social desirability bias in dietary self-report may compromise the validity of dietary intake measures. Int J Epidemiol, 24:389-98.

Heitmann BL, Lissner L, Osler M. 2000. Do we eat less fat, or just report so? Int J Obes Relat Metab Disord, 24:435-42.

Heitmann BL, Lissner L. 1995. Dietary underreporting by obese individuals - is it specific or non-specific? BMJ, 311:986-9.

Heitmann BL. 1993. The influence of fatness, weight change, slimming history and other lifestyle variables on diet reporting in Danish men and women aged 35-65 years. Int J Obes Relat Metab Disord, 17:329-36. 
Hirvonen T, Mannisto S, Roos E, et al. 1997. Increasing prevalence of underreporting does not necessarily distort dietary surveys. Eur J Clin Nutr, 51:297-301.

Horner NK, Patterson RE, Neuhouser ML, et al. 2002. Participant characteristics associated with errors in self-reported energy intake from the Women's Health Initiative food-frequency questionnaire. Am J Clin Nutr, 76:766-73.

Johansson G, Wikman A, Ahren AM, et al. 2001. Underreporting of energy intake in repeated 24-hour recalls related to gender, age, weight status, day of interview, educational level, reported food intake, smoking habits and area of living. Public Health Nutr, 4:919-27.

Johansson L, Solvoll K, Bjorneboe GE, et al. 1998. Under and over reporting of energy intake related to weight status and lifestyle in a nationwide sample. Am J Clin Nutr, 68:266-74.

Krebs-Smith SM, Graubard BI, Kahle LL, et al. 2000. Low energy reporters vs others: a comparison of reported food intakes. Eur J Clin Nutr, 54:281-7.

Lafay L, Basdevant A, Charles MA, et al. 1997. Determinants and nature of dietary underreporting in a free-living population: the Fleurbaix Laventie Ville Sante (FLVS) study. Int J Obes Relat Metab Disord, 21:567-73.

Lissner L, Heitmann BL, Bengtsson C. 2000. Population studies of diet and obesity. Br J Nutr, 83(Suppl 1):S21-4.

Livingstone MB, Black AE. 2003. Markers of the validity of reported energy intake. J Nutr, 133(Suppl 3):S895-920.

McCrory M, Hajduk C, Roberts S. 2002. Procedures for screening out inaccurate reports of dietary energy intake. Public Health Nutr, 5(6A):873-82.
Mennen LI, Jackson M, Cade J, et al. 2000. Underreporting of energy intake in four populations of African origin. Int $J$ Obes Relat Metab Disord, 24:882-7.

Mirmiran P, Azadbakht L, Mohammadi F, et al. 1382. Correlation of under and over reporting of energy intake to BMI and lifestyle related factors: Tehran Lipid and Glucose study (TLGS). Journal of Iran University of Medical Sciences, 10:111-22.

Pryer JA, Vrijheid M, Nichols R, et al. 1997. Who are the 'low energy reporters' in the dietary and nutritional survey of British adults? Int J Epidemiol, 26:146-54.

Samaras K, Kelly PJ, Campbell LV. 1999. Dietary underreporting is prevalent in middle-aged British women and is not related to adiposity (percentage body fat). Int J Obes Relat Metab Disord, 23:881-8.

Schoeller DA. 1999. Recent advances from application of doubly labeled water to measurement of human energy expenditure. J Nutr, 129:1765-8.

Schoeller DA. 2002. Validation of habitual energy intake. Public Health Nutr, 5(6A):883-8.

Vinken AG, Bathalon GP, Sawaya AL, et al. 1999. Equations for predicting the energy requirements of healthy adults aged 18-81 y. Am J Clin Nutr, 69:920-6.

Voss S, Kroke A, Klipstein-Grobusch K, et al. 1997. Obesity as a major determinant of underreporting in a self-administered food frequency questionnaire: results from the EPIC- Potsdam Study. Z Ernahrungswiss, 36:229-36.

Winkvist A, Persson V, Hartini TN. 2002. Underreporting of energy intake is less common among pregnant women in Indonesia. Public Health Nutr, 5:523-9. 